\title{
El tejido discursivo de una subjetividad Notas sobre la identidad *
}

Miguel Barahona*

\section{RESUMEN}

El objetivo de este escrito es presentar la identidad, ciudadanía y globalización desde una perspectiva del esencialismo teórico, desarrollándolo dentro de una totalidad emancipada. La identidad demanda conocer las particularidades desde la representación de la nación, la cultura, el género y la etnicidad, entre otras; por lo que se ha conformado una propuesta reivindicativa dentro de las coordenadas y visiones particulares de diferentes autores.

En tal sentido, a medida que se desarrollen los temas, se acercará al límite de la crítica donde el terreno de la argumentación se esgrime desde el sentido de la reinterpretación misma que se aproxima a una evidencia y a una redefinición de la misma producción identitaria.

Palabras clave: Identidad, ciudadanía, globalización, nación, género, etnicidad, cultura, sociedad, identidad nacional.

\section{ABSTRACT}

The objective of this writing is to present the identity, citizenship and globalization from a theoretical essentialism perspective, which is developed into a fully emancipated way. The identity demands to know all the particularities, such as the representation of nation, culture, gender and ethnicity, among others; reason why a claiming proposal within the coordinates and particular visions of different authors has been made.

In such sense, as the themes are developed, it will approach the critical limit where

\footnotetext{
"Este tema y trabajo de investigación fue concebido en el Diplomado Superior Universitario en "Identidades, Ciudadanía y Globalización en Centroamérica, 2009-2010". Curso realizado en la Universidad Centroamericana (UCA) y en el Instituto de Historia de Nicaragua y Centroamérica (IHNCA); beca de estudio auspiciada por la Fundación Ford para el fortalecimiento de la enseñanza de las Ciencias Sociales en las Universidades de la Región Centroamericana.

${ }^{1}$ Universidad Nacional Autónoma de Honduras. Facultad de Humanidades y Arte. Escuela de Letras miguel.barahona@yahoo.es
} 
the ground of the argument is put forward from the same sense of reinterpretation; which is closer to evidence and a redefinition of the same production of identity.

Key words: Identity, citizenship, globalization, nation, gender, ethnicity, culture, society, and national identity. 


\section{INTRODUCCIÓN}

\section{La perspectiva y reiteración en la producción de la identidad}

Al interior de los enfoques más racionalistas, el problema de la identidad se enmarca en la interpretación que hacen los individuos dentro de una estructura social y cultural. Se puede señalar que la discusión sobre identidad resulta imposible de resolver cuando se trata de desafiar los diversos paradigmas teóricos, debido a que éstos no sólo están constituidos por unas "teorías dominantes", sino que también forman parte de estudios relativos a las ciencias humanas de índole antropológico, histórico, psicológico y sociológico. De esta forma al tratar de hacer un análisis de la identidad desde la perspectiva de la identidad nacional, ésta pasa a constituirse como la teoría dominante que incluye la manera de ver la realidad "del mundo" y su modo de vida, a través de un lente particular, que al final da como resultado una visión estrecha, subjetiva, marginal y etnocentrista. Debido a lo anterior vamos a considerar los propuestos de Anthony D. Smith, quien enumera las características de la identidad nacional en base a los siguientes preceptos:

1. Un territorio histórico o patria.

2. Recuerdos históricos y mitos colectivos.

3. Una cultura de masas pública y común para todos.

4. Derechos y deberes legales e iguales para todos los miembros.

5. Una economía unificada que permite la movilidad territorial de los miembros ${ }^{1}$.

En consecuencia, cada uno de estos criterios se convierten en los ejes teóricos y paradigmáticos que sirven de vasos comunicantes para los vínculos sociales que comparten todos los individuos que conviven en un determinado Estadoterritorio. Estas relaciones de índole social, político e ideológico son las que legitiman cada elemento de la identidad interpretado como un "reduccionismo teórico", es decir: "todo es en base a una negación de los conceptos claves de la teoría que se intenta comprender e interpretar ${ }^{2 "}$.

En el caso de la teoría del fundamento de la identidad se puede partir de los conceptos expuestos por Hroch, quien razona desde una dimensión histórica con

\footnotetext{
${ }^{1}$ Smith D, Anthony. "La identidad nacional y otras identidades" en: Bibliografía Introductoria Diplomado Superior en Identidades, ciudadanía y Globalización. INHCA (comp.) Nicaragua: INHCA-UCA, 2008, pág. 22.

${ }^{2}$ Ernest, Nagel. La estructura de la ciencia, Nagel propone: "las expresiones características de una ciencia (...) son inteligibles en términos de las reglas o hábitos de esta disciplina, se las debe entender en los sentidos que se les ha asociado dentro de ésta...". Cap. XI. "La reducción de teorías", pág. 323.
} 
el aparente de que la identidad surgió y se extendió con éxito a través de diversos factores sobresalientes conocidos como objetivos, mismos que son independientes de los deseos y de las representaciones individuales ${ }^{3}$.

Así, en el nombre de la identidad se alude a unas conceptualizaciones que parten de sensibilidades, de ideas y de estados en correspondencia a una nueva realidad social: "la del proceso de construcción de la identidad", que reemplaza a una realidad agotada; la de nación. Si la conciencia de identidad se levanta sobre las ruinas de la nación, es preciso esclarecer la naturaleza de esta última. La conciencia de nación nace como producto de dos grandes procesos históricos de la humanidad, el primero, un proyecto ilustrado burgués de emancipación humana: el de la Revolución Francesa, que pretende elevar a la nación al plano político; y el segundo, el de la Revolución Industrial, que enmarca la nación dentro del plano económico.

La nación desde el espacio histórico centroeuropeo, por no decir el occidental, se caracteriza por una serie de rasgos como el gran proyecto de emancipación humana, el culto que impulsa el dominio ejercido del hombre sobre los hombres y también aquel de carácter progresivo e histórico, que tiene como característica principal el proceso lineal y ascendente dentro del cual se vinculan todos los individuos que constituyen la nación en base a las ideas de enfoque; donde sobresalen cada uno de los atributos históricos, simbólicos y culturales de la identidad étnica ${ }^{4}$. Un componente esencial de nación es el de hacer hincapié en el pasado colectivo y la preeminencia de ciertos individuos sobre otros. La nación como propuesta de identidad pretende regirse por la razón, por el dominio de la existencia de ciertacolectividad histórica muy particular.

Al interior de esta perspectiva particular y totalizante, se da lugar al surgimiento de diversos problemas conceptuales dentro de la racionalidad y la autocognoscibilidad de los sujetos, es decir, confronta la creencia en la inteligibilidad de la historia nacional y la confianza en la autodefinición del individuo por medio de la identidad nacional. Todos estos problemas los aborda A. Smith al decir que: "el proceso de autodefinición y ubicación es en muchos aspectos la clave de la identidad nacional, pero también es el elemento que ha suscitado más dudas y mayor escepticismo. Ante la gran variedad de actitudes y percepciones humanas, no tiene nada de

\footnotetext{
${ }^{3}$ Cfr Miroslav Hroch. "La construcción de la identidad nacional: del grupo étnico a la nación moderna" en: Bibliografía Introductoria Diplomado Superior en Identidades, Ciudadanía y Globalización. INHCA (comp.) Nicaragua: INHCA-UCA, 2008, págs. 62-63

${ }^{4}$ Véase "El estudio sobre la ethnia y etnogènesis"de Smith D, Anthony .Op. cit; págs. 30-32.
} 
extraño que los nacionalistas, sus críticos y todos los demás hayan sido incapaces de ponerse de acuerdo en los criterios de autodefinición y ubicación nacional ${ }^{5 "}$. Este modelo hegemónico-identitario, basado en el razonamiento histórico cultural, hace un balance a partir de un cuestionamiento de la historia como entidadidentidad. Al respecto, Gianni Vattimo nos dice que: "No existe una historia única, existen imágenes del pasado propuestas desde diversos puntos de vista, y es ilusorio pensar que exista un punto de vista supremo" (10-11).

Todos estos preceptos expuestos nos ubican dentro de un plano que contrasta con la crisis de la historia moderna; la cual enfatiza todas las dificultades que se dan entre las ideas de la nación en relación a la identidad y la etnicidad; ideas que transmiten una ambivalencia cuando se aborda al hombre como individuo y su relación con otros, es decir la pertenencia social colectiva.

Es así que la crítica del sentido de pertenencia nos traslada al pensamiento actual, que indica que todo individuo no sólo se debe centrar en los atributos de herencia identitaria, sino, al mismo tiempo debe negarlos. De esta visión se desprende la idea general que un individuo tiene dos vías para pertenecer a una categoría de comunidad étnica: la primera al formar parte del agrupamiento social-cultural, y la segunda vía posible es cuando el sujeto se adscribe sin condiciones al proyecto de emancipación nacional.

Ante este panorama es necesario preguntarse ¿Qué puede perder un individuo ante la situación de la identidad, en el contexto de la relación colectiva y la ubicación de este mismo individuo dentro de un proyecto de nación-nacionalista?. Al respecto, A. Smith menciona algunos de estos paradigmas al decir que: "En nombre de la «ldentidad nacional» las personas han estado de acuerdo en sacrificar sus propias libertades o recortar las de los otros; han estado dispuestas a pisotear los derechos civiles y religiosos de minorías étnicas, raciales y religiosas que las naciones no podían absorber".

Entonces, el término identidad nacional supone la total aceptación, por parte del individuo, de la entidad e identidad social -nacional de la cual forma parte. También la identidad nacional acepta la articulación de la nación ficticia modelada según

\footnotetext{
${ }^{5}$ Smith D, Anthony. "La identidad nacional y otras identidades" en: Bibliografía Introductoria Diplomado Superior en Identidades, ciudadanía y Globalización. INHCA (comp.) Nicaragua: INHCA-UCA, 2008, pág. 27.

${ }^{6}$ Vattino, Gianni. "Postmodernidad ¿Una sociedad transparente?" En torno a la postmodernidad. Ed. Anthropos. Barcelona, 1991, pág. 11.
} 
el esquema lógico, ideológico y nacionalista. Estas articulaciones niegan lo particular y estimulan la pertenencia colectiva por medio de la asimilación cultural, hacen que cada individuo acepte su propia condición de dominado social al reconocer la cuestión nacional como el ente superior instaurado e inquebrantable, al que se debe lealtad y obediencia. De esta forma el individuo concibe y adopta todos estos esquemas de identidad nacional, no obstante, en lo particular y en la práctica sean para cada sujeto fehacientemente negativos. Dichos esquemas sirven a cada individuo para justificar todo pensamiento y toda actitud dentro de "ese deber ciudadano" que debe cumplir sin discusión. Eric Hobsbawn alude que "al abordar la cuestión nacional se debe considerar que existen las ideologías oficiales de los estados y los movimientos no nos dicen lo que hay en el cerebro de sus ciudadanos o partidarios, ni siquiera de los más leales ${ }^{7}$.

De primera impresión, la mutación del pensamiento individual hacia la identidad nacional se instala en lo particular de cada ideología estatal. Es a partir de aquí donde cada individuo acepta la representación del sistema; aunque lo anterior dé como resultado a un sujeto vacío de sí y lo convierta en el reflejo de otros, es decir en una aparente identidad colectiva. En fin, el sujeto consiente la imagen donde él es un ser que existe sólo por medioy para la colectividad.

Uno de los tópicos más comunes sobre la concepción de la nación en las sociedades occidentales es la idea de pertenencia, la cual necesita tener un nacionalismo, un Estado-nación, una ideología oficial-estatal y, por supuesto, una evolución del nacionalismo dentro de las naciones ya establecidas ${ }^{8}$. Todos estos elementos son claramente determinantes en el contexto de las elaboraciones culturales que hacen las naciones, fundamentándose en una perspectiva histórica. Así, al utilizar estas elaboraciones, para caracterizar la nación, da lugar a resultados claramente erróneos y paralelamente ligados a una ideología que pretende imponer reglas sobre otros individuos; dando lugar a clasificaciones negativas de superioridad e inferioridad respectivamente.

En efecto, la competencia de un individuo frente al Estado no puede ser caracterizada con sólo recurrir y obedecer a una serie limitada de reglas y leyes totalmente rígidas. Existen muchos puntos fluctuantes en esta competencia, que dan lugar a una actuación individual mucho más abierta, más flexible y adaptable en oposición a todas aquellas caracterizaciones colectivas mediante un conjunto de

\footnotetext{
${ }^{7}$ Hobsbawm, Eric. "Naciones y Nacionalismo desde 1780, en: Bibliografía Introductoria Diplomado Superior en Identidades, Ciudadanía y Globalización. INHCA(comp.) Nicaragua: INHCA-UCA, 2008, pág. 82.

${ }^{8}$ Cfr Hobsbawm, Eric. "Naciones y Nacionalismo...”Op.cit; págs. 71-81.
} 
reglas omnipotentes, completamente definidas y establecidas que se deben cumplir con una actitud sumisa y no beligerante.

\section{Más allá de la identidad: Lo esencial y la diferencia}

Al examinar con detalle los temas de ciudadanía, y para llegar al final de este escrito, consideramos que en la primera noción de identidad y sociedad se puede percibir el arquetipo nacionalista identitario que se vive y se repite dentro de una colectividad. De esta manera concebimos que no es posible abordar esta temática desde una óptica individualista; debido a que ésta sólo es parte dentro de una dialéctica del cuerpo social y no representa toda una colectividad.

Debemos también observar como el individuo se enfrenta al dilema de la asimilación de nación-nacionalidad con la cual se identifica en primera instancia, como parte del grupo; pero después el individuo se sitúa dentro de un entorno social determinado, el cual le permite que empíricamente adopte, se adapte y acepte las ideas paroxísticas desarrolladas en el complejo sentido de la pertenencia ciudadana.

En efecto, la fusión de estas ideas da como resultado "La identidad funcional", esa que se hace en términos racionales e irracionales que enseñan y que reafirman el patriotismo como producto de un "aparente conformismo". Lo anterior se condensa en la idea expresada por Mauricio Virolli quien dice: "El redescubrimiento de la patria es recordado en el lenguaje del amor. Amor a lugares que de pronto se llenan de significado, de gentes que ahora consideramos cercanas y queridas. El lenguaje del patriotismo todavía se usa para sostener el compromiso con el ideal de república, mientras que el lenguaje del nacionalismo (o la variación de él, que actualmente se denomina comunitarismo) es utilizado para llamar a la homogeneidad cultural, ética y religiosa... ".".

Hay que precisar, que este emplazamiento puede ser revelador en la yuxtaposición de las ideas del conjunto humano. Aquí nos encontramos ante una paradoja traducida como la ciudadanía, que sin duda da paso a una serie de caracterizaciones por parte del individuo frente a la experiencia de la nacionalidad. Experiencia que parte de un punto: el de la unificación colectiva en un determinado espacio-territorial y donde se logran cristalizar las causas y los

\footnotetext{
${ }^{9}$ Virolli, Mauricio, "Epílogo. Patriotismo sin nacionalismo" en: Bibliografía Introductoria Diplomado Superior en Identidades, ciudadanía y Globalización. INHCA(comp.) Nicaragua: INHCA-UCA, 2008, págs. 327-328.
} 
ideales grupales; simbolizados dentro de un marco o proyecto nacional donde las representaciones: espaciales -sociales,y las físicas-correlativas, van a identificar al sujeto dentro de un determinado espacio que le sirve de "refugio"; ese lugar que constituye su hogar denominado el terruño, es decir La Patria.

En efecto, si la nacionalidad se caracteriza por la idea de residencia, ideología, sexo, clases ya establecidas y delimitadas, es decir, una identidad que tiene nombre, apellido y dirección física, es una identidad que posee un conjunto de leyes determinadas "racionalmente" y sobre todo artificiosas. Lo anterior resulta incoherente porque no se cumple a cabalidad, debido a que toda nación se construye a base de unas redes que nacen, se desarrollan, se entrecruzan, se relacionan, se diluyen y al final desaparecen para dar paso a otras redes, es decir; la nación es producto de la evolución versátil en la compleja y agitada red colectiva, la llamada sociedad humana.

Sin lugar a dudas, este punto de referencia nos conduce a través del laberinto de la sinergia fundamentada en las masas, misma que permite considerar la nación como la estructura de la duplicidad y multiplicidad. Sinergia que conlleva a creer en lo ideal y se desencanta en lo concreto y subjetivo, es decir, en el contexto del signo social: "El patriotismo es diferente a la abnegación heroica. El primero requiere que hagamos algo más que atender a nuestros asuntos privados, el segundo exige el sacrificio de nuestras preocupaciones personales e incluso de nuestra vida por el bien común... En momentos de decaimiento extremo de la vida pública, puede que surja un sentido de dignidad y de honor patriótico para sostener la virtud cívica. Sin embargo, tenemos muchos ejemplos de interminable aguante y de adaptación a la corrupción y a la opresión: no hay caminos que conlleven con seguridad al renacimiento de la virtud cívica... ${ }^{10 " .}$

\section{CONCLUSIÓN}

Nuestra visión de la nación y nacionalidad, así como de la ciudadanía y el patriotismo no deben ser considerada un arcaísmo anacrónico porque todos estos conceptos enmarcan a cada sociedad dentro de una ubicación en determinado tiempo y espacio, dentro de una posición y un sustrato correlacionados entre sí. Todo desequilibrio provocado por la ausencia de cada uno de estos factores, puede conducir a una confusión social dentro de la aceptación del individuo y la sociedad. Así la reafirmación y aceptación de las diferencias debe ser lo

\footnotetext{
${ }^{10}$ Ibid; págs. 339-340.
} 
imperativo dentro de todas las aspiraciones humanas. La nación se debe concebir en el marco de una relación social intrínseca que conlleve al reconocimiento de los individuos y todos sus aspectos tanto los físicos, los intelectuales y los emocionales.

La verdadera Identidad, debe ubicar o reubicar a cada sujeto dentro del territorio nacional después de considerar, reconocer y respetar ciertos aspectos individuales tan básicos como son: la movilidad social, la inmigración, la emigración y la fuerza de trabajo. Asimismo la nación debe proveer y promover todos los códigos sociales, políticos y morales que convierten al sujeto en un ciudadano nacional. Esto conlleva a la búsqueda de re-localizar la imaginación y la aspiración de una nación a través de los movimientos de las distintas sociedades que conviven en un determinado territorio; movimientos en pos de la aceptación de la identidad, en el supuesto de que en un mundo globalizado debe existir un lugar para la interconexión y la aceptación multicultural, multiétnica y plurilingüista. Así que nuestra aldea global debe ser internacionalizada, y la misma debe relegar al olvido todos los causales históricos de los grandes desastres sociales en contra de la humanidad; realizados en todos los tiempos por las "grandes" naciones, así por ejemplo tenemos el exacerbado nacionalismo, el separatismo autonómico impuesto, el tribalismo y la xenofobia; males que a lo largo de la historia humana se han repetido una y otra vez.

Lo anterior exige un autoexamen para que cada nación le corresponde reinterpretar las fronteras sociales y debe concebir que las diferencias no son irreconciliables, al contrario, son aquellas que denotan la uniformidad humana, de tal forma que las diferencias son una identidad racional-referenciada, donde se pueden construir las bases sociales de la nación, por medio de una macrocultura en la microcultura de la integración. En este siglo XXI debemos ser testigos de la creación e instalación de la Identidad universalista, bajo la premisa de olvidar todos aquellos idealizados míticos sentimientos nacionalistas. Se debe crear una Identidad que permita el dislocamiento de las utopías, de todas las supremacías de ciertas sociedades y de culturas monopólicas, que hacen valer su preeminencia a costa del sometimiento de todas las sociedades que ante sus ojos les resultan "inferiores". Así cada nación debe abrir un sendero hacia la investidura de la universalidad de la identidad.

En definitiva, el gran aliado para esta cruzada de cambios sobre el concepto de identidad, es el reconocimiento de la convergencia cultural, como una política que debe servir para fortalecer la sociedad en general sin hacer ningún tipo de distinción. La sensibilidad individual y colectiva hacia la Identidad posibilitará 
reconstruir el mundo, y de igual forma impulsará en cada sujeto una visión universalista de pensar y practicar la solidaridad. Así que la solidaridad como producto social tiene como mérito la virtud transpolítica, la lógica de la identidad, la pluralidad y la tolerancia.

En conclusión: El pluralismo transforma cada nación, la singulariza y la totaliza de forma racional. Eso apunta precisamente a que la Identidad es la aceptación de la diferencia.

\section{BIBLIOGRAFÍA}

Anderson, Benedict. "Introducción en: Comunidades imaginadas. Reflexiones sobre el origen y la difusión del nacionalismo. México: fondo de cultura económica, 1991. Págs. 17-25.

Calhou, Craig. "Parentesco, etnicidad e identidades categóricas", en: Nacionalismo. Buenos Aires: Libros El zorzal, 2007. Págs. 55-113.

Favre, Henri. "Capítulo V. Del indigenismo al indianismo", en: El indigenismo. México: Fondo de cultura económica, 1998. Págs. 126-147.

González y González, Luis. "Terruño, microhistoria y ciencias sociales", en: Región e historia en México. México: Instituto Mora/UAM , 1991. Págs. 23-36.

Habermas, Jürgen. "Identidad nacional e identidad post nacional", en: Identidades nacionales y post nacionales. España, Tecnos, 1994. Págs. 11-121.

Hroch, Mkiroslav. "La construcción de la identidad nacional: del grupo étnico a la nación moderna en: Revista de Occidente, No. 161". Octubre 1994. Págs. 4560.

Hobsbawn, Eric. "Introducción en naciones y nacionalismo desde 1780". Barcelona: Crítica, 1991. Págs. 9-21.

Krauskopf, Dina. "Dimensiones y pertenencias en la construcción de las identidades juveniles en Centroamérica", en: Estudios culturales centroamericanos en el nuevo milenio. Marc Zimmerman y Gabriela Baeza Ventura (coords.) Houston: LACASA, 2007.

Kinloch, Francés. "Naciones y nacionalismo. Debates en torno a sus análisis históricos", en taller de Historia No. 6, Nación y etnia ¿Identidad natural o creación cultural? Nicaragua: IHNCA-UCA, 1994. Págs. 9-31.

Stavenhagen, Rodolfo. "Los escollos de la etnicidad y los conflictos étnicos", en: Conflictos étnicos y estado nacional. México: siglo XXI, 2000. Págs. 23-46.

Smith, Anthony. "La identidad nacional". España. Trama. 1997.

Van Young, Erick. "Haciendo historia regional: consideraciones metodológicas y teóricas", en: Región e historia en México (1700-1850). Pérez H, Pedro (comp.). México: Instituto Mora/UAM, 1991. Págs. 99-122. 
Vattino, Gianni. "Postmodernidad ¿Una sociedad transparente?" En torno a la postmodernidad. Ed. Anthropos. Barcelona, 1991.

Virrolli, Mauricio. "Epílogo. Patriotismo sin nacionalismo", en: Por amor a la patria. España, Acento, 1997. 202-Págs. 232.

Viveros Vigoyas, Mara. "El concepto de género y sus avatares: Interrogantes en torno a algunas viejas y nuevas controversias", en: Pensar (en) género. Teoría y práctica para nuevas cartografías del cuerpo. Millán de Benavides, C. y Estrada A. (eds.). Bogotá: Universidad Javeriana, 2004. Págs. 170-191.

Wade, Meter. "Capítulo I" en Raza y etnicidad en Latinoamérica. Ecuador: Abya Yala, 2000. Págs. 11-34. 